\title{
Sustainability within Technical Engineering Curriculum - A Hydraulic Fracturing Module in Fluid Mechanics
}

\author{
Ryan Anderson, Paul Gannon, Carolyn Plumb \\ Montana State University, Bozeman MT, USA
}

A transferable module is presented that brings sustainability topics into a core chemical engineering fluid dynamics course. A topic was chosen based on technical applicability to the course and current debate on the topic. In this case, hydraulic fracturing ('fracking') was chosen for the connection to course content (e.g. pumps, porous media flows) and its widespread debate in the United States ${ }^{1}$. On the day of the activity, a guest instructor first surveyed the students with questions on their understanding of and opinion on topics within fracking. The students were then shown two short videos on the topic, one from a science-focused group ${ }^{2}$ and one from an industrial proponent of the fracking technology ${ }^{3}$. After the videos, students were sorted into five theme areas: science/technology, economics, policy, society, and the environment. These areas were chosen to highlight the breadth of topics that must be engaged in order to approach such complex problems. Further, it is a move toward interdisciplinary learning within engineering curricula where students consider broader societal themes as part of an engineering solution ${ }^{4}$. Students brought a research device for this day, and all students had access to laptops or various smart phone devices. During the in-class activity, the students in their groups engaged in their own research on the topic using a variety of web-based sources. As they found information relevant to their theme area, they took notes and then brought that into a group accumulation of relevant information. With this data compiled, one representative from each area summarized salient points to the entire class. A course-wide $(n \sim 40)$ discussion ensued with facilitation from the guest instructor. Beyond that day of integration, the course instructor aimed to show the importance of such topics via three practices. First, the course objective 'Students will analyze engineering problems in the context of economics, technology, society, and the environment' was added to the course syllabus along with ten other objectives focused on more traditional technical content. Second, after the activity, a homework assignment was given on material balances and pump sizing requirements associated with a typical hydraulic fracturing site to directly connect the technical course content to the broader focus of the fracking activity. Lastly, a bonus problem on the final exam asked students "If you were a landowner, would you allow hydraulic fracturing (fracking) on your land? Briefly explain your answer." Select survey results from Fall 2017 are chosen to highlight students' selfreported understand of and support for fracking (pre-post responses), if the class-format was effective in their learning, and open ended comments relating to changes in their opinion and the course format. The transferability of this module is discussed, along with ways to translate the concept to other courses, such as into a heat transfer course via a nuclear power module.

1 ASEE PRISM Features, "Get Fracking" - Thomas K. Grose, September 2011

2 "Animation of Hydraulic Fracturing (fracking)" - Marathon Oil:

https://www.youtube.com/watch?v=VY34PQUiwOQ Accessed May 2017

3 "Facts About Fracking" - SciShow: https://www.youtube.com/watch?v=51wOisfdIPo\&list=PL73C8A01C82C423CB

Accessed May 2017

${ }^{4}$ National Academy of Engineering (2005). Educating the Engineer of 2020. National Academies Press. 